\title{
THE MATHEMATICS PROGRAM OF THE OFFICE OF NAVAL RESEARCH
}

The Mathematics Branch of the Office of Naval Research (ONR) has now been in operation for over a year. During that time support of mathematical research in the United States has been extended primarily to universities; and it seems appropriate to give to the members of the American Mathematical Society some account of the philosophy which has determined the mathematical research projects which ONR is sponsoring. The effectiveness of the program in strengthening mathematical research in the United States is largely dependent upon the cooperation of the mathematical community. This cooperation has been generously offered by many mathematicians during the past year; and it is hoped that the present account will inform a wider mathematical public of ONR's activities. It should perhaps be explained immediately that ONR has no statutory power to make grants, or award fellowships; so that all the activity which is here reported takes the form of contracts between the Navy and the university or other research institution.

The Office of Naval Research is committed primarily to the support of fundamental research in the sciences, as contrasted with development, or with applications of known scientific results - the types of activity in which scientists were largely engaged during the war. This is a basic policy decision which recognizes that the United States must be strong scientifically if it is to be strong militarily. It is natural, however, that the most obvious types of mathematical research which would seem to warrant Navy support would be research in applied directions such as those set forth in the recent report of the Society's Special Committee on Applied Mathematics. ${ }^{1}$ And it is a fact that over $4 / 5$ of the annual mathematics expenditure is in support of research in "applied mathematics," mathematical statistics, numerical analysis and computing devices. This last category includes a rather large expense for the construction of an electronic digital computer, and for the partial support of the National Applied Mathematics Laboratories which are currently being set up by the National Bureau of Standards. It includes also almost the entire support of the computing group formerly known as Mathematical Tables Proj-

\footnotetext{
${ }^{1}$ Instruction and research in applied mathematics, prepared by the Special Committee on Applied Mathematics and approved by the Council of the American Mathematical Society, Bull. Amer. Math. Soc. vol. 53 (1947) pp. 639-640.
} 
ect, which has been assimilated into the National Applied Mathematics Laboratories, and which will, in the future, derive its principal support from other sources. Mention is made of these special activities in an attempt to put ONR's financial commitments in perspective. For, although appropriations for theoretical studies in mathematics represent less than $1 / 5$ of the annual total, the number of contracts with theoretical objectives is more than $1 / 3$ of the entire group.

Early in the course of the operation of the Mathematics Branch, it was decided as a matter of policy that sound support of mathematical research in this country must include support of work in pure mathematics, and a portion of the budget was accordingly allocated for that purpose. Thus one of the earliest projects supported by this office was a project in conformal mapping, some aspects of which were reported to the Society at its 1946 Los Angeles meeting by Professor D. C. Spencer of Stanford University. Other projects which are now on the books of ONR include work on spectral theory for normal operators in function spaces; research on free groups; a systematic study of relationships between analytic and measure theoretical concepts of surface area with a view to applications in the theory of the calculus of variations; work on the analytic number theory of prime number distribution, with special reference to the representation of primes by polynomials; investigation of random chemical, physical and biological processes; and a study of deformations in topology. Certain of these contracts were entered into on the basis of the recommendations of a committee (consisting of Professors J. von Neumann, G. C. Evans, H. M. Morse, M. H. Stone, H. Whitney, O. Zariski) set up by the National Academy of Sciences to act as advisers to the Mathematics Branch on questions connected with projects in pure mathematics, and to suggest the most promising contracts in support of post-doctoral research by young mathematicians. Others represent partial support of research undertaken by relatively senior mathematicians during their sabbatical leaves of absence. There are several contracts which involve research on differential equations, both linear and nonlinear, but with special emphasis on problems connected with nonlinear partial differential equations. It is hardly necessary to point out that in every case the research proposal originates with the principal investigator. In every case, the principal criteria which determine the Navy's willingness to enter into a contract are the research records of the senior workers under the contract, and the judgment of mathematicians who have been outstanding contributors to the field of research in question as to the potential mathematical significance of the proposed investigations. Mathematicians have been exceed- 
ingly generous in giving the Mathematics Branch the benefit of their advice in connection with proposals for the support of mathematical research whenever such advice has been sought, and in assisting in the formulation of general policy. An aspect of this general policy which is of special interest to many readers of the Bulletin is ONR's desire, within the general framework of its budget and in accordance with the criteria already mentioned, to provide assistance to universities which are taking steps to strengthen their research activity in either pure or applied mathematics, and particularly in parts of the country which lack strong research centers.

Activity in the applied phases of mathematics which occupied a relatively minor place in the research life of this country in 1940 is now drawing the interest of an increasing number of our ablest scholars. Mathematical statistics is playing an ever more important role in our scientific and industrial life; and many competent people believe that the scope and power of applied mathematics will be affected in an important way by the high speed digital computers which are now under development. Activities in mathematical statistics and in computer theory and development, along with research in the classical fields of applied mathematics which in the past have engaged the interest of some of the greatest figures in mathematical history, are deemed by the Office of Naval Research to be of the greatest importance in the development of the scientific strength of the country. Thus, in addition to supporting research in pure mathematics, the Mathematics Branch is attempting to (1) assist the work of able groups which are active in applied fields, (2) facilitate the formation of strong new research groups in these fields, (3) provide for the training, by leaders in applied mathematics, and on the level of basic mathematical research, of promising young men who are interested in these activities, and (4) make the results of work in these fields available generally to the Navy and to the scientific workers of the country.

It may be remarked parenthetically that ONR encourages publications of research results in the usual mathematical periodicals and in books. In the case of two translations of Russian books which have been prepared under ONR contracts, one, Interior problems of the theory of schlicht functions, by G. M. Golusin, has been printed in a limited edition by ONR because no other form of publication seemed feasible; while the other, Theory of oscillations, by Andronow and Chajkin is to be published by the Princeton University Press. In general, dissemination through established channels is greatly preferred to private distribution. 
A vigorous development of applied mathematics has begun abroad, particularly in Russia, Germany, England, and Holland; and ONR is attempting to assist a similar development in this country. It may be of interest to indicate some of the types of research which are supported under this heading. Under a broad contract with New York University, a principal field of research has been gas-dynamics (the so-called Shock Wave Manual which was prepared during the war has undergone a complete revision and should be published shortly). Another related topic studied systematically under this contract is the mathematical theory of gravity waves in water. Previous research in the theory of underwater explosions has been carried forward. Other topics in mathematical physics have been studied ranging from the theory of two-dimensional free jets to various topics in wave propagation and to perturbation theory of linear operators in a continuous spectrum. At Brown, ONR sponsored research is concerned with a critical survey of recent contributions in the field of elastic-plastic and purely plastic deformations of solids, particularly research carried on during the war and in the post-war years. A comprehensive review of the entire field of plasticity has been made which resulted in the determination of five subfields for immediate investigation-crystal plasticity, the plastic behavior of quasi-isotropic materials, stressstrain relations for quasi-isotropic materials in the plastic range, theories of integration, and a critical survey of the classical theory of plasticity and its applications. Another project in applied mathematics in which a number of striking results have been obtained is a study of the dependence of the electrostatic capacity of a conductor or system of conductors upon its geometrical configuration. ONR is also assisting in the establishment of a review journal, Applied Mechanics Reviews, to succeed the defunct Zentralblatt für Mechanik. This new journal is jointly sponsored by the American Mathematical Society, the American Society of Civil Engineers, the Society for Experimental Stress Analysis, the American Society of Mechanical Engineers, the American Institute of Physics, and the Institute for Aeronautical Sciences; and is to be published by the American Society of Mechanical Engineers. It is expected that the first issue will appear in January 1948.

In mathematical statistics, some of the research fields covered are Small Sample Theory, at Princeton; Factorial Design of Experiments, at Iowa State; Multivariate Analysis, and Statistical Analysis of Groups of Experiments, at the University of North Carolina; and Statistical Theory of Multi-Valued Decisions at Columbia. In computing and computing equipment, some of the activities have already been mentioned. One contract of interest which has not been men- 
tioned supports the development of an analog machine to provide for two-dimensional Fourier Analysis for use in studies of crystal structure.

In the projects which were in force in June 1947, there were 36 senior mathematicians and 46 graduate students in applied mathematics, 16 senior research workers and 26 graduate students in mathematical statistics, 42 senior scientists and 38 graduate students on computing projects, and 36 senior mathematicians and 10 graduate students on pure mathematics projects. It will be seen that one of the most important by-products of this program is the training of promising young mathematicians. Thus the inclusion of able Ph.D. candidates as junior research workers under ONR contracts is encouraged. Since there is no restriction on the publication of research results, it is possible to prepare a Ph.D. thesis as part of the research performed under the contract.

It is believed that the program currently supported by ONR is enabling many productive mathematicians to expand and strengthen their normal research activities, and to assist in the accelerated training of promising young research workers; while able junior mathematicians are, in several cases, being given the opportunity to carry on their investigations for an additional year, before assuming their university duties.

It is hoped that the impact of this program on the mathematical life of the United States will be in the direction of stimulating significant mathematical research, and of enabling the faculties of universities in all parts of the country to encourage the interest in mathematical research of their most promising students. It is expected that this activity will contribute toward the production of a gradually increasing corps of able and experienced mathematical research workers.

In its broad outline, the ONR program reflects the Navy's recognition that intensive research in certain fields of applied mathematics may be counted upon to yield specific results directly applicable to engineering and other scientific problems and therefore of use to industry and research laboratories as well as to Naval establishments; but it reflects also the recognition that a lively activity in mathematical research and a sustained growth in the number of mathematically trained personnel are necessary to enhance the scientific life of this country and to maintain the position of the United States relative to scientific progress abroad.

\author{
Mina ReEs, \\ Head, Mathematics Branch, \\ Office of Naval Research
}

